\title{
Cytogenetic Studies of Normal and Cleft-Palate Epitheliums in Mice
}

\author{
CARLOS E. NASJLETI, HERBERT H. SPENCER, JOHN BLANKENSHIP, and \\ JAMES M. WALDEN
}

Veterans Administration Hospital and the University of Michigan, Ann Arbor, Michigan 48105

This study investigated teratogenic activity on a cellular level through analysis of the cytogenetic complex in cleft-palate epithelial cells from the progenies of mice treated with cortisone. Analysis showed no detectable aberration from a normal chromosomal complement.

Cleft of the primary and secondary palate in human beings is a frequent congenital malformation occurring once in 800 live births. In Michigan, this congenital defect is incident once in 740 live births. ${ }^{2}$ Although both genetic and environmental forces are involved in cleft formation, the genetic mechanism has not been described adequately or have specific environmental agents been identified. Research continues to seek the pathogenesis and the etiologic factors for cleft deformity.

The report of Gropp, Jussen, and Odunjo ${ }^{3}$ of a near-triploid epithelial cell oulture derived from the palatal mucosa of a child with cleft palate and lip aroused great interest in the possibility that other persons with cleft palate would have abnormal ohromosomal patterns. Reports on the karyotypic findings in human cleft-palate tissues have been conflicting. Soukup and Warkany ${ }^{4}$ reported cytogenetic studies in cultures of palatal tissues from six patients with cleft palate, of which all but one also had cleft lip. These investigators found no chromosome abnormalities in their group of children. Similarly, Jackson ${ }^{5}$ reported a modal number of 46 , with karyotype analyses of modal cells consistent with the phenotypic sex in each of eight instances of cleft-palate tissue cultures. On the other hand, Murphy and Reisman, ${ }^{6}$ in cultured

Received for publication January 13, 1969. cells derived from the cleft-palate explants of ten children, reported a high incidence of chromosomal heteroploidy reflected in a general increase in tetraploidy or neartetraploid metaphases. In three of these children, a mixed population of diploid and aneuploid cells was present.

Recently, in this laboratory, it was demonstrated that many teratogens, such as ionizing radiation and chemotherapeutic agents, produce chromosomal aberrations in human somatic cells both in vivo and in vitro. ${ }^{7-10}$ It was also demonstrated that one single injection of cortisone given at $121 / 2$ days of gestation into pregnant mice induced $83.3 \%$ incidence of cleft palate in their progenies. ${ }^{11}$ The question arose whether cleft palate induced by a teratogen-like cortisone is also associated with chromosomal abnormalities.

Tissue-culture procedures as reported in other previous cytogenetic studies provide a good source of cells in mitosis for karyologic analyses. ${ }^{3-6,12-14}$ However, work in this laboratory demonstrated that aneuploid and polyploid karyotypes appeared much more frequently in tissue-culture material than in cells not subjected to culturing procedures. ${ }^{15}$ It was observed that cells in tissue culture have a tendency for heteroploidy transformation. ${ }^{16}$ Because some of the chromosomal abnormalities reported in human cleft-palate tissues may have arisen from the in vitro environmental condition, the chromosomes of cortisone-induced cleftpalate cells of mice (Mus musculus) were studied. Cells were processed without an intervening culture period. This study attempted to investigate teratogenic activity on a cellular level through analysis of the cytogenetic complex in cleft-palate epithelial cells from the progenies of mice exposed to 
cortisone. However, the intent of the study was not to suggest a transmissible change in the genotype but only to define further the magnitude of the action of cortisone on the tissues of the mouse.

\section{Materials and Methods}

Pregnant $\mathrm{A} / \mathrm{Jax}$ mice, ${ }^{*} 8$ to 10 weeks of age at breeding, were used in all experiments. Pregnancy was dated by mating large numbers of mice of both sexes for a single night, isolating the females, and selecting the obviously pregnant mice on the 12th day of pregnancy. A standard laboratory diet $\bar{\dagger}$ and water were given ad libitum. All mice were killed on the 19th day of gestation.

Ten mice were assigned to two experimental groups. Group 1, composed of five females, received a single intramuscular injection of $7.5 \mathrm{mg}$ cortisone acetate $(0.3$ $\mathrm{ml}$ of Cortone saline suspension $¥$ which was given at $12^{1 / 2}$ days of pregnancy. Group 2 (control), composed of five females, received a single intramuscular injection of $0.3 \mathrm{ml}$ sterile physiologic saline solution given at the same time as the cortisone administration to group 1 . Three hours before death, all mice were given intramuscular injections of $0.025 \mathrm{mg}$ vinblastine sulfate diluted in $0.01 \%$ sterile isotonic saline, $\S$ to arrest cell division at metaphase. All mice were killed by dislocation of the atlas. The fetuses were recovered by laparotomy, observed under the dissecting microscope at $\times 30$ magnification, and inspected for the presence of clefts. The paired homotypic palatal shelves from 20 fetuses with cleft palate from the cortisone-treated group, as well as the complete secondary palate from each of 20 normal fetuses from the control group, were removed (Fig 1). Separately, normal-palate and cleft-palate pooled tissues were placed in $50-\mathrm{ml}$ covered beakers containing Hanks' balanced salt solution with penicillin and streptomycin at final concentration of 100 units and $100 \mu \mathrm{gm} / \mathrm{ml}$, respectively. Aliquots of solution and tissues were placed in sterile petri plates, where the epitheliums were dissected out and

\footnotetext{
* Jackson Memorial Laboratories, Bar Harbor, Me.

† Purina Laboratory Chow, Ralston Purina Co., St. Louis, Mo.

$\ddagger$ Merck \& Co., West Point, Pa.

$\S$ Velban, Eli Lilly \& Co., Indianapolis, Ind.
}

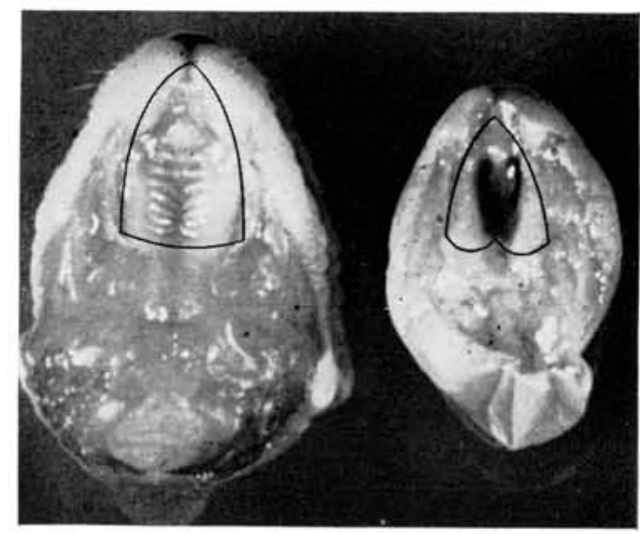

FIG 1.-Normal (left) and induced (right) cleft-palate specimens of mice.

underlying connective tissues were removed and discarded.

CHROMOSOME PREPARATION.-Immediately after excision, these palatal epithelial tissues were minced with fine scissors in tissue-culture medium 199\| containing $0.25 \%$ trypsin and $1 \mathrm{ppm}$ of colcemid.\# Tissue fragments were then transferred into 50-ml Erlenmeyer flasks and stirred gently for five minutes, after which the fluid was decanted off and spun down. The supernatant was discarded and fresh medium 199 containing trypsin and colcemid was added. The mixture continued to trypsinize at a moderate rate for 45 minutes longer. Epithelial cell suspensions were then transferred to conical centrifuge tubes and centrifuged at $500 \mathrm{rpm}$ for ten minutes. The supernatant was decanted, and the packed cells were resuspended in $0.9 \%$ sodium citrate for 30 minutes at $37 \mathrm{C}$. Cells were again spun down and fixative ( 3 parts absolute ethyl alcohol to 1 part glacial acetic acid) was added slowly with constant agitation. The cells were left in this fixative in the refrigerator until just before the preparation of the chromosome spreadings, when they were spun down and the fixative was removed. The cells were resuspended in two changes of fresh fixative. A drop of cell suspension in fixative was placed on a cold slide and immediately held over a spirit flame until completely dry. The slides were stained in Giemsa stain, dehydrated, cleared, and mounted in Euparal.9

\footnotetext{
\| Difco, Detroit, Mich.

\# CIBA Pharmaceutical Co., Summit, NJ.

ฯ George T. Gurr, Ltd., London, England.
} 
Photographing Chromosomes. - All slides were coded and evaluated blindly. Slides were scanned for mitotic metaphases under the microscope, and, when possible, a minimum of 300 cell mitoses from each of the two cell samples were photographed. Well-spread mitoses were selected under low magnification $(\times 312.5)$, and chromosomes were scored under oil immersion $(\times 1,250)$. The photographs of these cells were taken on $35-\mathrm{mm}$ film with an AO-X oil-immersion objective, an achromatic condenser, and the standard photographic ocular supplied with the universal Zeiss microscope. A Wratten 58 green filter increased contrast, facilitating counting and photography. High-contrast copy film was used and developed in D-76 at $20 \mathrm{C}$ with continuous agitation for ten minutes. The $2 \times 2$-inch transparencies obtained were projected on a screen for study.

CHRomosome aNALYSIS.-Examination was carried out on metaphase chromosomes that appeared intact and with the count tentatively established. Once a cell was selected under low power, it was included in the tabulations. Types and frequencies of chromosome abnormalities as well as the distribution of numbers of chromosomes per cell were scored. Abnormalities scored were gross structural changes which could be detected without detailed karyotype analysis, such as chromatid and chromosome breaks. chromatid exchanges, and chromosomal translocations. No attempt was made to assess minor aberrations such as chromatid gaps, small deletions, and small differences in chromosomal size. Also, the cells were checked for numerical variations of the diploid chromosomal number, such as aneuploidy, heteroploidy, and polyploidy.

The aforementioned experiment was repeated twice, and the cytogenetic analysis demonstrated almost identical results.

\section{Results}

Chromosome metaphases from the palatal mucosa of the secondary palate from 20 fetuses of the control group were normal in number as well as in morphology. The only variations seen were those attributed generally to murine-type cells and to artifacts arising during chromosome preparations. Of 300 cell mitoses counted and analyzed for chromosomal damage in this group, $82 \%$ had 40 telocentric chromosomes (Fig 2), $10 \%$ were aneuploid metaphases which had missing or in excess of one or two chromosomes, and $8 \%$ were tetraploid metaphases with 80 randomly distributed chromosomes (Fig 3). Endoreduplicated polyploid mitoses were not observed in this control material. However, $7 \%$ chromatid breaks and $4 \%$ chromosomal breaks were detected (Fig 3).

In the cells derived from the epitheliums of the cortisone-induced cleft-palate shelves, the mitotic figures were apparently normal. Of 300 cells analyzed in this group, $80 \%$ had 40 chromosomes, $10 \%$ were aneuploids, and $10 \%$ were tetraploids. These cell metaphases demonstrated $6 \%$ chromatid breaks and $6 \%$ chromosomal breaks.

\section{Discussion}

Under these experimental conditions, all observations indicate that cells derived from the epitheliums of untreated normal secondary palate and those from cortisone-induced cleft-palate mice have similar chromosome

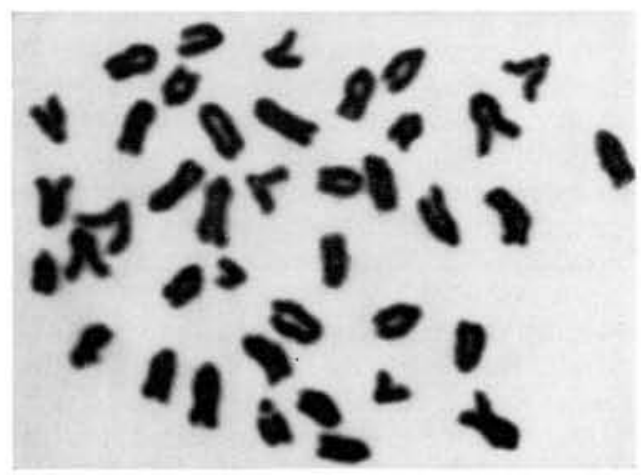

FIg 2.-Diploid epithelial cell metaphase of mice with 40 chromosomes.

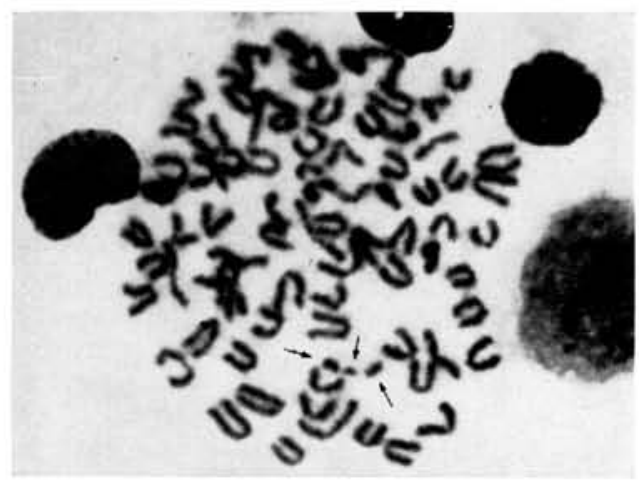

FIG 3.-Tetraploid epithelial cell mitosis of mice showing chromosomal breakage (arrows). 
complements. There were no noticeable differences in the chromosome constitution between the cells from control and from cleft-palate mice. The findings do not substantiate a hypothesis that a teratogenic dose of cortisone will produce visible changes in somatic mice chromosomes. These results are consistent with Major's ${ }^{12}$ recent findings, at which time tetratogenic dosages of cortisone were given on the 11 th, 12 th, 13 th, and 14th days of gestation to pregnant mice; cortisone did not induce visible alteration in the number or in the structure of the cytogenetic complex of their offspring. $\mathrm{He}$ studied liver cells, where the diploid karyotype predominated in preparations obtained directly from the embryo and in preparations derived from primary tissue cultures. Heteroploidy occurred much more frequently in cells cultured by in vitro technics than in cellular preparations obtained by in vivo procedures. In this study, polyploidy appeared very infrequently in liver cells of the 19-day mouse fetus.

Previously, Ingalls, Ingenito, and Curley ${ }^{13}$ reported chromosomal aberrations in mice somatic cells induced by 6-aminonicotinamide. These authors demonstrated polyploidy in a high percentage of maternal and embryonic cells. They also showed fragmentation of chromosomes, thus indicating a structural as well as a numerical alteration of the genome. In addition, analysis of maternal bone marrow showed that the genetic component suffered cytogenetic damage similar to that observed in tissue cultures. Hence these investigators hypothesized that once a chromosomal injury is induced, the impact may reach to the subsequent generations of cells descending from the injured cell. They further suggested studies to test whether the palatal defect itself is an expression of chromosomal aberration or whether the congenital deformity is the direct result of injury to primordial tissue.

Gropp et $\mathrm{al}^{3}$ processed epithelial cell cultures from palatal mucosa within four weeks after explantation for cytogenetic analysis. Chromosome karyotypes of 30 metaphases revealed a modal number of 72 chromosomes, including one supernumerary small metacentric chromosome. These investigators suggested that a change of the karyotype in the culture cells arising from a genetic or chromosomal instability of un- known nature, or even an accidental change of the karyotype during cultivation in vitro, seemed improbable because of the lack of aneuploidy other than the type found in their study. In another study, ${ }^{6}$ specimens of palatal mucosa from the margins of cleft palate in ten children were analyzed for chromosome anomalies. The tissue cultures revealed a high incidence of chromosomal heteroploidy, and, in three of the tissue explants, revealed aneuploidy and mosaicism.

The results of the studies of Gropp et $\mathrm{al}^{3}$ can be explained as a local chromosome anomaly arising early after zygote formation or in the precursor cells of the blastema responsible for the formation of the oropalatal region. From the point of view of Murphy and Reisman, ${ }^{6}$ however, improper embryonic-tissue growth patterns during the development of the cleft-palate defect might lead to localized chromosomal anomalies. Also, in a small proportion of the sporadic cases of cleft palates, the presence of chromosome mosaicism might cause asynchronous development of the growth centers with failure of coalescence and fusion. Nevertheless, these two reports indicate that the cytology of cleft-palate tissues were positive for chromosome anomalies, and, accordingly, were consistent with the concept that these anomalies may provide the genetic instability which ultimately results in cleftpalate deformity. Conversely, Muramoto, Aya, and Sasaki ${ }^{14}$ in eight patients and, separately, Subrt, Cervenka, and Krecek ${ }^{17}$ in 11 patients with cleft palate described a normal modal number of chromosomes with no morphologic changes in cells analyzed from these patients. Subrt et $a^{1-}$ stated, "Since chromosome abnormalities have been consistently associated with severe defects affecting several systems, one would not expect to demonstrate cytogenetic aberrations in a condition so limited as cleft palate and/or lip. ${ }^{11}$

It is still too early to assess the significance of these various findings. The general lack of success in consistently identifying abnormalities in chromosomal patterns characteristic of either induced or congenital cleft palate emphasizes the complexity of this deformity.

The findings of the current investigation do not substantiate a visible change in the chromosomal complement of mice-induced 
cleft-palate cells. Nevertheless, since numerical and structural changes in the chromosomes of experimental mice ${ }^{13}$ and human beings ${ }^{3,6}$ have been associated with the occurrence of cleft palate as an isolated abnormality, one might conjecture that some cases of cleft palate possess concurrent changes in chromosomes, either as the cause or as an accompanying feature of the deformity.

\section{Conclusions}

Embryos with cleft palate were produced by injecting cortisone acetate into pregnant A/Jax mice. The palatal shelves were removed from the normal and the cleftpalate embryos and, after preparation, were examined for chromosomal changes. The chromosomal patterns in cells from the palatal mucosa of the secondary palate did not differ from the pattern seen in cells derived from the epitheliums of the cortisone-induced cleft-palate shelves. Metaphase figures from both sources were apparently normal. The only variations seen were those attributed generally to murine-type cells and to artifacts arising during chromosome preparations.

Hence under these experimental conditions, the present study does not substantiate a hypothesis that cortisone will produce visible changes in mice chromosomes.

\section{References}

1. Greene, J.C.; Vermillion, J.R.; Hay, S.; GibBENS, S.F.; and Kerschbaum, S.: Epidemiologic Study of Cleft Lip and Cleft Palate in Four States, JADA 68:389-402, 1964.

2. Michigan Cripled Children's CommisSION: Annual Report, 1959.

3. Gropp, A.; Jussen, A.; and OdunJo, F.: Near-Triploid Chromosome Constitution in Epithelial-Cell Cultures of Palatal Mucosa from a Case of Cleft Palate, Lancet 1: $1167,1964$.

4. Soukup, S., and Warkany, J.: Chromosomes in Cleft-Palate Tissues, Lancet 1: 492-493, 1966.

5. JACkson, J.F.: Chromosomes in CleftPalate Tissues, Lancet 1:1156, 1966.
6. MurPhy, J.W., and Reisman, L.E.: Chromosomes in Cleft-Palate Tissues, Lancet 11:228-229, 1966.

7. Nas.Jleti, C.E.; Walden, J.M.; and SpenCER, H.H.: Polyploidization and Aberration of Human Chromosomes Induced In Vitro and In Vivo with Ionizing Radiations, $J$ Nucl Med 7:159-176, 1966.

8. NASJleti, C.E., and SPENCER, H.H.: Chromosome Polyploidization in Human Leukocytes Induced by Radiation, Ann NY Acad Sci 155:748-758, 1968.

9. NAsjleti, C.E.; Walden, J.M.; and SPenCER, H.H.: Polyploidy and Endoreduplication Induced In Vivo and In Vitro in Human Leukocytes with N,N'-bis-(3-bromopropionyl) Piperazine (A-8103), Cancer Res 25:275-285, 1965.

10. NASJleti, C.E., and SPencer, H.H.: Chromosome Damage and Polyploidization Induced in Human Peripheral Leukocytes In Vivo and In Vitro with Nitrogen Mustard, 6-Mercaptopurine, and A-649, Cancer Res 26:2437-2443, 1966.

11. Nas.leti, C.E.; Avery, J.K.; Spencer, H.H.; and WaldeN, J.M.: Tritiated Cortisone Distribution and Induced Cleft Palate in Mice, J Oral Ther 4:71-83, 1967.

12. MAJOR, M.W.: A Study of the Eflect of Cortisone on the Chromosomes of Somatic Cells of the Nineteen-Day Fetal Mouse, unpublished MS thesis, University of Michigan School of Dentistry, 1964.

13. INGALlS, T.H.; INGENITO, E.F.; and CURLEY, J.J.: Acquired Chromosomal Anomalies Induced in Mice by Injection of a Teratogen in Pregnancy, Science 141: 810-812, 1963.

14. Muramoto, H.; Aya, T.; and Sasaki, M.: Chromosome Study of Patients with Cleft Lip and Cleft Palate Based on Lesion Biopsies in Culture, Jap J Hum Genet 11: 31-35, 1966.

15. Nasjleti, C.E., and Spencer, H.H.: Unpublished data.

16. BARSKI, G.: "Cytogenic Alterations in Mixed Cultures of Mammalian Somatic Cells In Vitro," in Harris, R.J.C. (ed): Cytogenetics of Cells in Culture, Vol. 3, New York and London: Academic Press, 1964.

17. Subrt, I.; Cervenka, J.; and Krecek, M.: Cytogenetic Study of Cleft Lip and Palate, Cleft Palate J 3:362-367, 1966. 